\title{
Enkapsulasi dan Karakterisasi Pelepasan Terkendali Pupuk NPK Menggunakan Kitosan Yang Ditaut Silang Dengan Glutaraldehida
}

\author{
Jayanudin Jayanudin ${ }^{\mathrm{a} *}$ dan Retno Sulistyo D. Lestari ${ }^{\mathrm{b}}$ \\ $a^{*}$ Jurusan Teknik Kimia, Universitas Sultan Ageng Tirtayasa Jl. Jenderal Sudirman km.3 Cilegon-Indonesia \\ 42435 \\ ${ }^{b}$ Indonesian-Center of Excellence for Food Security, Universitas Sultan Ageng Tirtayasa \\ Jl. Raya Jakarta Km 4 Pakupatan, Serang-Indonesia 42118 \\ * Corresponding author \\ E-mail: jayanudin@untirta.ac.id
}

DOI: 10.20961/alchemy.16.1.34711.110-125

Received 27 Septemeber 2019, Accepted 27 January 2020, Published 01 March 2020

\begin{abstract}
ABSTRAK
Pelepasan terkendali pupuk NPK bertujuan untuk meningkatkan efisiensi penggunaan unsur hara tanaman dan juga untuk mengurangi pencemaran lingkungan. Penelitian ini bertujuan untuk menentukan pengaruh konsentrasi larutan kitosan dan glutaraldehida terhadap yield dan daya serap mikrokapsul pupuk NPK. Tujuan lain adalah menentukan karakterisasi dan analisis release pupuk NPK dari mikrokapsul dan juga menghitung kinetika release. Mikrokapsul pupuk NPK dipreparasi dengan mencampurkan pupuk NPK cair ke dalam larutan kitosan, kemudian campuran tersebutkan diteteskan ke dalam larutan glutaraldehida sambil diaduk. Mikrokapsul pupuk NPK yang terbentuk dicuci menggunakan petroleum eter dilanjutkan dengan heksana dan dikeringkan. Hasil penelitian menunjukkan bahwa peningkatan konsentrasi larutan kitosan dan glutaraldehida menghasilkan peningkatan yield, menurunkan daya serap air, dan menurunkan pupuk NPK yang release dari mikrokapsul pupuk NPK. Model kinetika release yang sesuai berdasarkan tingginya nilai $\mathrm{R}^{2}$ adalah model order satu dan model Higuchi didapat dari mikrokapsul pupuk NPK yang dipreparasi dengan $1 \%(\mathrm{~b} / \mathrm{v})$ larutan kitosan dan $5 \%(\mathrm{v} / \mathrm{v})$ larutan glutaraldehida.
\end{abstract}

Kata kunci: glutaraldehida, kinetika release, kitosan, mikrokapsul, pupuk NPK

\begin{abstract}
Encapsulation and Characterization of Controlled Release of NPK Fertilizer Using Glutaraldehyde-Crosslinked Chitosan. Controlled release NPK fertilizer aims to improve the nutrient use efficiency (NUE) of plants and also to reduce environmental pollution. This study aims to determine the effect of the concentration of chitosan and glutaraldehyde solutions on the yield and absorptive ability of NPK fertilizer microcapsules. Another objective was to determine the characterization and analysis of NPK fertilizer releases from microcapsules and also to calculate the release kinetics. NPK fertilizer microcapsules were prepared by mixing liquid NPK fertilizer into a chitosan solution, and then the mixture was dripped into a glutaraldehyde solution while stirring. NPK fertilizer microcapsules formed were washed using petroleum ether, followed by hexane and dried. The results showed that an increase in the concentration of chitosan and glutaraldehyde solutions resulted in an increase in yield, decreased water absorbency, and lower NPK fertilizer released from microcapsules. The appropriate release kinetics models based on the higher $\mathrm{R}^{2}$ value were the first-order model and the Higuchi model obtained from microcapsules of NPK fertilizer that was prepared with $1 \%(\mathrm{w} / \mathrm{v})$ chitosan solution and $5 \%(\mathrm{v} / \mathrm{v})$ glutaraldehyde solution.
\end{abstract}

Keywords: Glutaraldehyde, release kinetics, chitosan, microcapsule, NPK fertilizer 


\section{PENDAHULUAN}

Pupuk berfungsi untuk memberikan tambahan unsur hara bagi tanaman untuk pertumbuhan dan kualitas tanaman. Unsur hara terpenting adalah nitrogen $(\mathrm{N})$, fosfor $(\mathrm{P})$, dan kalium (K). Pupuk mampu meningkatkan 50\% hasil panen, namun pemupukan yang kurang optimal atau berlebihan dapat menurunkan efisiensi penggunaan pupuk dan selanjutnya dapat mengarah pada rusaknya lingkungan dan ekologi (Jing et al., 2017; Chen et al., 2018).

Peningkatan konsumsi pupuk tidak diimbangi oleh efisiensi penggunaannya. Pupuk konvensional memiliki efisiensi penggunaan nutrisi (unsur hara) (nutrient use efficiency) yang rendah dari kemampuan tanaman untuk memperoleh nutrisi, mengangkutnya ke dalam akar dan memindahkannya ke bagian lain dari tanaman. Efisiensi penggunaan nutrisi dari unsur hara makro seperti $\mathrm{N}$, $\mathrm{P}$, dan $\mathrm{K}$ masing-masing mencapai 30-35\%, 1820\%, dan 35-40\% (Guo et al., 2018). Hal ini berarti sekitar 40-70\% N, 80-90\% P, dan 50$70 \% \mathrm{~K}$ dari pupuk yang digunakan hilang ke lingkungan dan tidak diserap oleh tanaman. Hilangnya unsur hara ini disebabkan karena pencucian oleh curah hujan, irigasi, dan aliran air. Unsur hara $\mathrm{N}$ dan $\mathrm{P}$ yang hilang ke lingkungan menyebabkan kerugian ekonomi dan menyebabkan masalah lingkungan seperti polusi, pencemaran air tanah eutrofikasi di lingkungan perairan. Melimpahnya kandungan unsur hara dalam tanah menyebabkan ketidakseimbangan unsur hara dan rantai makanan dalam ekosistem (Guo et al., 2018; Wu and Liu, 2008; Himmah et al., 2018).

Solusi yang dapat dilakukan untuk meningkatkan efisiensi penggunaan pupuk dan meminimalkan polusi tanah dan air adalah menggunakan pupuk pelepasan terkendali (controlled release fertilizer). Jenis pupuk ini merupakan cara untuk memasok unsur hara secara bertahap dan sesuai dengan kebutuhan untuk tanaman. Pupuk pelepasan terkendali mampu mengontrol pelepasan unsur hara selama periode waktu yang lama (Himmah et al., 2018; Sempeho et al., 2014).

Salah satu pembuatan pupuk pelepasan terkendali adalah proses enkapsulasi dimana pupuk dibungkus dengan lapisan polimer atau biopolimer. Metode-metode enkapsulasi pupuk yang sudah dilaporkan seperti metode gelasi ionotropik dengan kitosanpati sebagai penyalutnya (Perez and Francois, 2016). Biopolimer yang dapat digunakan selain kitosan adalah alginat atau gabungan antara kitosan-alginat untuk melapisi pupuk urea (Danarto et al., 2017), atau pupuk NPK yang disalut menggunakan carboxymethyl cellulose (Olad et al., 2018). Modifikasi-modifikasi tersebut mempunyai tujuan yang sama yaitu meningkatkan efisiensi penyerapan nutrisi (pupuk) oleh tanaman tetapi metode yang 
digunakan tidaklah sederhana, seperti metode gelasi ionotropik yang sensitif terhadap perubahan $\mathrm{pH}$. Metode ini tidak akan berhasil jika $\mathrm{pH}$ campuran tidak sesuai. Metode lain adalah spray dryer, metode ini tidak dapat digunakan untuk slurry (campuran padat-cair) karena dapat menyumbat atomizer (nozzle), kelemahan lainya adalah biaya instalasi yang mahal.

Pada penelitian ini metode pembuatan mikrokapsul pupuk NPK untuk pelepasan terkendali menggunakan kitosan sebagai matriks yang ditaut silang dengan glutaraldehida karena lebih sederhana dibandingkan dengan metode-metode yang sudah dilaporkan sebelumnya. Kitosan yang ditaut silang dengan glutaraldehida mampu meningkatkan kestabilan dengan membentuk senyawa perantara (Savana and Maharani, 2018). Kitosan sebagai bahan matrik juga mempunyai kelebihan yaitu bersifat hidrofilik yang mampu menahan air yang menyebabkan unsur hara terlepas dari pupuk (Danarto et al., 2017). Penggunaan kitosan yang ditaut silang dengan glutaraldehida juga sudah dilaporkan oleh Jayanudin et al., (2019a), tetapi untuk membuat mikrokapsul oleoresin jahe merah yang digunakan sebagai antioksidan. Kelebihan lain dari penggunaan kitosan karena bersifat biodegradabel dan biokompatibel.

Tinjauan khusus yang menjadi tujuan dari penelitian ini adalah pengaruh konsentrasi larutan kitosan dan glutaraldehida terhadap yield mikrokapsul pupuk NPK yang terbentuk, karakterisasi pelepasan terkendali (controlled release) pupuk NPK dalam medium air, dan penentuan kinetika release mikrokapsul pupuk NPK.

\section{METODE PENELITIAN}

Penelitian ini menggunakan bahan-bahan sebagai berikut: Pupuk NPK cair merk BaimGrow yang diproduksi Sinar Agri Jawa Barat, Larutan glutaraldehida grade analisis dengan konsentrasi 25\% dari Merck, larutan heksana dan petroleum eter grade teknis dari CV. Tri Jaya Dinamika. Kitosan diperoleh PT. Biotech Surindo yang mempunyai derajat deasetilasi $(\mathrm{DD})=87,2 \%$ dan viskositas $37,10 \mathrm{cps}$. Asam asetat glasial $100 \%$ diperoleh dari Merck. Peralatan penelitian yang digunakan adalah magnetik stirer dan oven kirin model KBO-90M.

\section{Proses enkapsulasi pupuk NPK cair}

Proses persiapan enkapsulasi pupuk NPK cair dimulai dengan melarutkan kitosan dengan asam asetat glasial dengan konsentrasi 1\% (v/v). Konsentrasi larutan kitosan yang digunakan dalam penelitian ini adalah 1, 2, 3, dan 4\% (b/v). Pupuk NPK cair dengan volume $30 \mathrm{~mL}$ dicampur dengan $60 \mathrm{~mL}$ larutan kitosan kemudian diaduk menggunakan 
magnetik stirrer dengan kecepatan 500 rpm selama 30 menit. Setelah campuran diaduk, kemudian tambahkan ke dalam 150 mL larutan glutaraldehida (konsentrasi glutaraldehida yang digunakan adalah 3, 5, 7, dan 10\% (v/v)). Penambahan campuran larutan kitosan dengan pupuk NPK cair dilakukan tetes demi tetes sambil diaduk dengan kecepatan 500 rpm. Setelah selesai, campuran masih terus diaduk selama 2 jam untuk proses reaksi taut silang. Mikrokapsul pupuk NPK yang terbentuk di saring dan dicuci menggunakan petroleum eter dilanjutkan dengan heksana, kemudian dikeringkan dalam oven dengan suhu $65{ }^{\circ} \mathrm{C}$. Mikrokapsul pupuk NPK yang terbentuk dianalisis yield, analisis daya serap air, karakterisasi dan uji release mikrokapsul pupuk NPK dalam medium air.

\section{Analisis mikrokapsul pupuk NPK}

\section{Yield}

Yield enkapsulasi dihitung menggunakan Persamaan (1) yang menunjukkan rasio antara berat mikrokapsul NPK dengan berat campuran kitosan dan pupuk NPK cair.

$$
\% \text { Yield }=\frac{\text { berat mikrokapsul pupuk NPK }}{\text { berat total campuran kitosan dan pupuk NPK cair }} \times 100 \%
$$

\section{Daya serap air (DA)}

Analisis daya serap air dari mikrokapsul pupuk NPK menggunakan modifikasi dari metode yang dilaporkan oleh Liang and Liu (2006). Sebanyak 1 g mikrokapsul pupuk NPK kering direndam dalam $50 \mathrm{~mL}$ air pada suhu ruang selama 24 jam. Mikrokapsul pupuk NPK yang menyerap air disaring untuk menghilangkan air yang tidak terserap dan ditimbang. Air yang terserap per gram mikrokapsul NPK kering dihitung menggunakan persamaan (2).

$$
D A=\left(\frac{M}{M_{0}}-1\right) \times 100 \%
$$

Dimana $M$ adalah berat mikrokapsul NPK yang menyerap air dan $M_{0}$ mikrokapsul NPK kering.

\section{Karakterisasi mikrokapsul NPK menggunakan Scanning Electron Microscopy (SEM) dan Fourier-Transform Infrared Spectroscopy (FTIR)}

Analisis morfologi mikrokapsul pupuk NPK menggunakan SEM merk JEOL tipe JSM-6510LA. Mikrokapsul dilapisi platinum. Model resolusi high vacuum (HV) adalah $3.0 \mathrm{~nm}(30 \mathrm{kV})$, model low vacuum adalah $4.0 \mathrm{~nm}(30 \mathrm{kV})$ dan akselerasi tegangan berkisar dari 0,5 kV-30 kV. Analisis mikrokapsul dengan FTIR tipe spektrofotometer Shimadzu IR menggunakan pellet $\mathrm{KBr}$ dioperasikan antara 500 sampai dengan $4000 \mathrm{~cm}^{-1}$. 


\section{Analisis pelepasan terkendali (controlled release) pupuk NPK dalam medium air}

Analisis pelepasan terkendali pupuk NPK dalam medium air digunakan untuk menentukan jumlah pupuk NPK yang terlepas dari mikrokapsul. Sebanyak 0,2 g direndam dalam $50 \mathrm{~mL}$ selama 1, 3, 7, 14, 21, dan 30 hari pada suhu ruang. Untuk analisis jumlah pupuk NPK yang lepas dari mikrokapsul menggunakan spektrofotometer UV-Vis tipe Thermo Scientific Genesys 10 uv. Panjang gelombang yang digunakan untuk menentukan nilai absorbansi pada setiap sampel adalah dengan memindai panjang gelombang maksimal dari pupuk NPK cair dan diperoleh panjang gelombang sebesar $415 \mathrm{~nm}$. Konsentrasi pupuk NPK yang lepas ke medium air dihitung dari regresi non linier dari absorbansi standar. Konsentrasi pupuk NPK yang release ke medium air kemudian dilakukan perhitungan kinetika release menggunakan model dari Persamaan (3) - (7) yang mengacu pada penelitian yang dilaporkan oleh El-Nashar et al. (2016), Dash et al. (2010), DozieNwachukwu et al. (2017), dan Jayanudin et al. (2018).

$$
\begin{aligned}
& \text { Order Nol } \\
& \frac{M_{t}}{M_{\infty}}=k_{0} t \\
& \text { Order Pertama } \\
& \frac{M_{t}}{M_{\infty}}=1-\exp \left(-\mathrm{k}_{1} \mathrm{t}\right) \\
& \text { Model Higuchi } \\
& \frac{M_{t}}{M_{\infty}}=\mathrm{k}_{\mathrm{H}} \mathrm{t}^{1 / 2} \\
& \text { Model Korsmeyer-Peppas } \\
& \frac{\mathrm{M}_{\mathrm{t}}}{\mathrm{M}_{\infty}}=\mathrm{k}_{\mathrm{K}-\mathrm{P}} \mathrm{t}^{\mathrm{n}} \\
& \text { Model Hixon-Crowell } \\
& \mathrm{W}_{0}^{1 / 2}-\mathrm{W}_{\mathrm{t}}^{1 / 2}=\mathrm{k}_{\mathrm{H}-\mathrm{C}} \mathrm{t}
\end{aligned}
$$

Dimana, $\frac{\mathrm{M}_{\mathrm{t}}}{\mathrm{M}_{\infty}}$ adalah kumulatif release pupuk NPK, $\mathrm{k}_{0}, \mathrm{k}_{1}, \mathrm{k}_{\mathrm{H}}, \mathrm{k}_{\mathrm{K}-\mathrm{P}}$, dan $\mathrm{k}_{\mathrm{H}-\mathrm{C}}$ adalah konstanta dari order nol, order pertama, model Higuchi, model Korsmeyer-Peppas, model Hixon-Crowell, dan model $\mathrm{n}$ adalah mengindikasikan mekansme release, $W_{0}$ adalah jumlah pupuk NPK awal dalam mikrokapsul, $W_{t}$ adalah jumlah pupuk NPK sisa.

\section{HASIL DAN PEMBAHASAN}

\section{Yield mikrokapsul pupuk NPK}

Enkapsulasi pupuk NPK menggunakan penyalut kitosan yang ditaut silang dengan larutan glutaraldehida telah sukses dilakukan. Mikrokapsul pupuk NPK ini dibuat berdasarkan perubahan konsentrasi larutan kitosan dan glutaraldehida. 


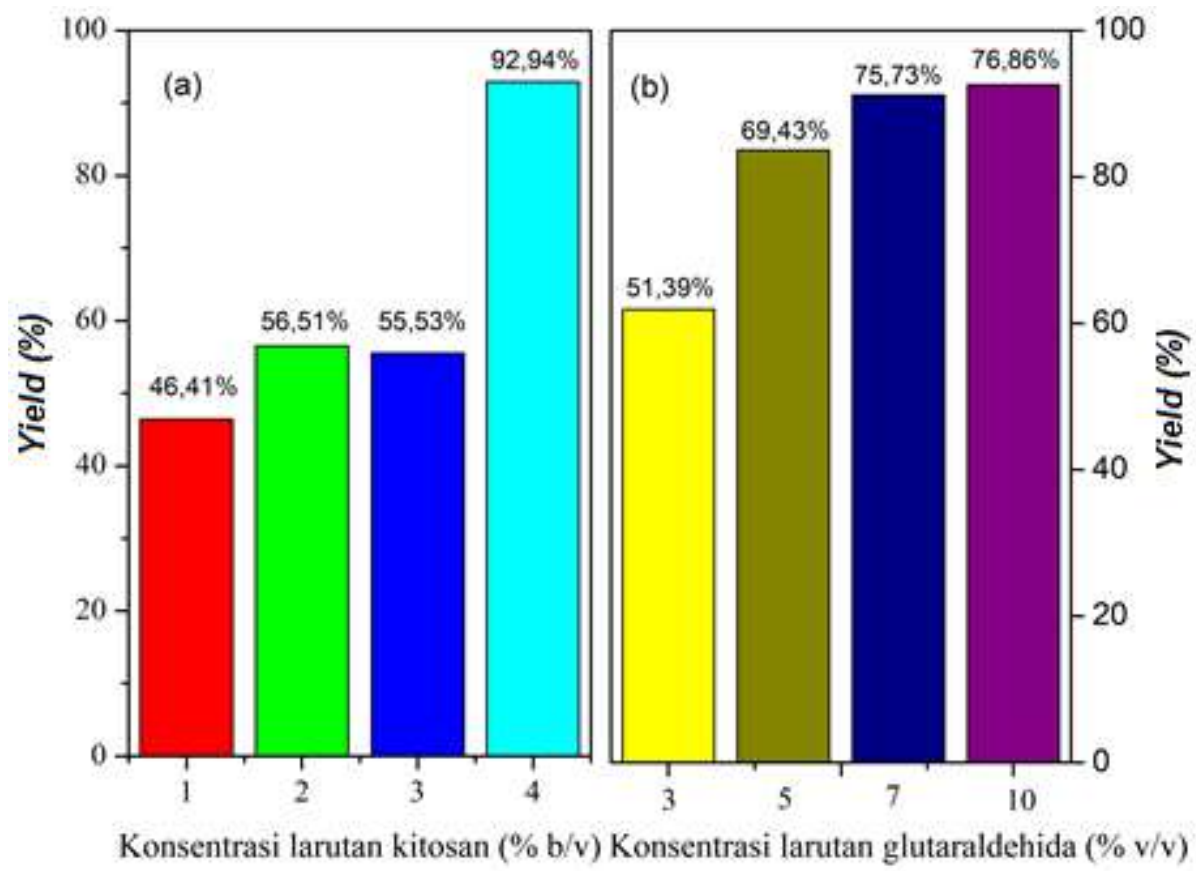

Gambar 1. Yield mikrokapsul pupuk NPK berdasarkan (a) pengaruh perubahan konsentrasi larutan kitosan pada konsentrasi larutan glutaraldehida sebesar 5\% dan (b) pengaruh konsentrasi larutan glutaraldehida sebagai agen crosslink dengan konsentrasi larutan kitosan sebesar $2 \%(\mathrm{~b} / \mathrm{v})$.

Gambar 1 memperlihatkan bahwa peningkatan konsentrasi larutan kitosan sebagai bahan penyalut dan larutan glutaraldehida sebagai agen crosslink mampu meningkatkan yield mikrokapsul pupuk NPK. Kenaikan yield yang signifikan terjadi ketika menggunakan larutan kitosan dengan konsentrasi $4 \%(\mathrm{~b} / \mathrm{v})$, sedangkan perubahan konsentrasi larutan glutaraldehida tidak mengalami kenaikan yield yang signifikan. Reaksi crosslink yang terjadi antara gugus amina dari kitosan dengan gugus aldehida dari glutaraldehida meningkat karena konsentrasi keduanya meningkat sehingga mikrokapsul pupuk NPK yang terbentuk semakin banyak. Yield tertinggi terjadi pada mikrokapsul pupuk NPK yang dibuat dari konsentrasi larutan kitosan 4\% (b/v) yang ditaut silang dengan glutaraldehida dengan konsentrasi 5\% (v/v) sebesar 92,94\% dan yield terendah diperoleh dari mikrokapsul yang disiapkan dari 1\% (b/v) larutan kitosan dan ditaut silang dengan 5\% (v/v) larutan glutaraldehida sebesar 46,41\%.

\section{Analisis daya serap air}

Analisis daya serap air dibutuhkan untuk mengetahui kemampuan bahan dinding mikrokapsul dari kitosan yang ditaut silang dengan glutaraldehida dalam menyerap air. Analisis ini berpengaruh pada laju release yang akan terjadi pada mikrokapsul pupuk 
NPK. Gambar 2 menunjukkan bahwa peningkatan konsentrasi larutan kitosan dan glutaraldehida menurunkan kemampuan mikrokapsul pupuk NPK dalam menyerap air.

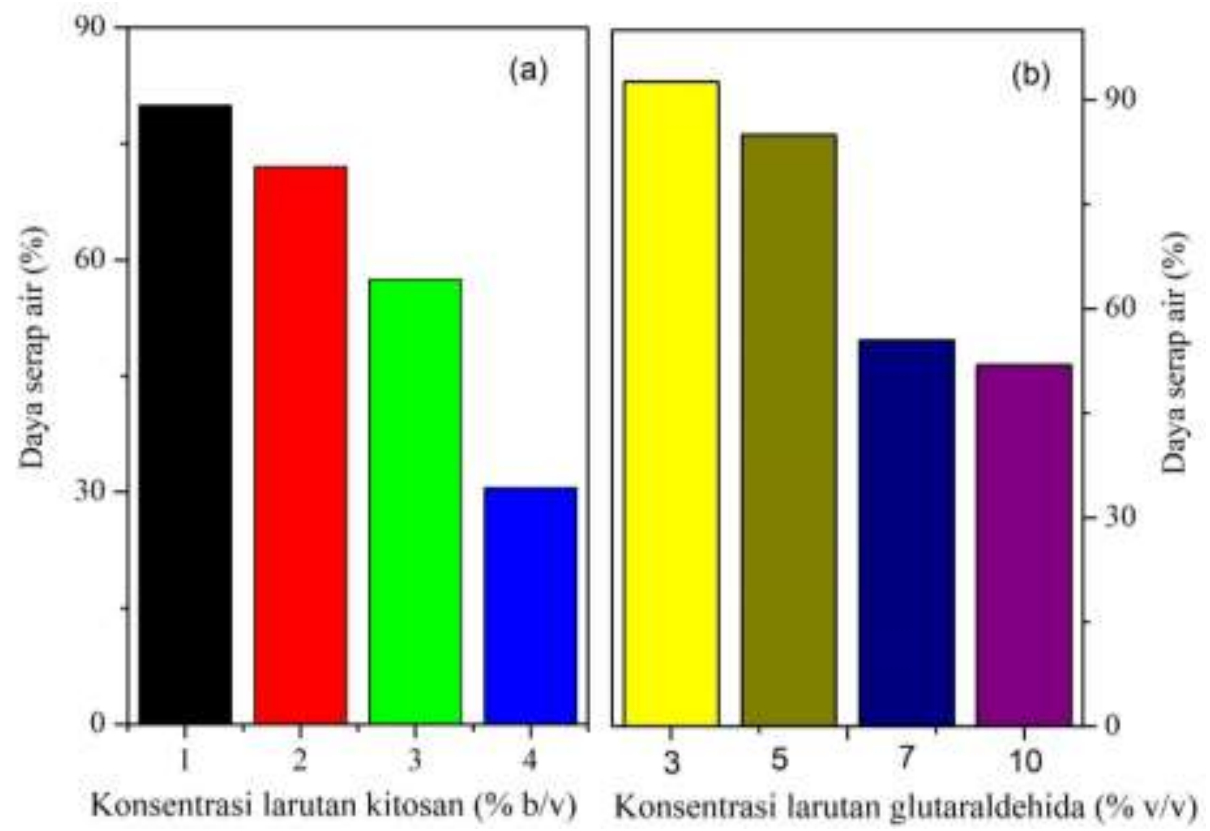

Gambar 2. Perubahan daya serap air dari mikrokapsul pupuk NPK dipengaruhi oleh: (a) perubahan konsentrasi larutan kitosan, (b) Perubahan konsentrasi larutan glutaraldehida.

Daya serap air untuk konsentrasi larutan kitosan $1 \%(\mathrm{~b} / \mathrm{v})$ sampai dengan 3\% (b/v) tidak mengalami penuruan yang signifikan, akan tetapi ketika larutan kitosan dengan konsentrasi 4\% (b/v) mengalami penuruan yang drastis. Hal ini dapat disebabkan karena pada konsentrasi larutan kitosan $4 \%(\mathrm{~b} / \mathrm{v})$ terbentuk jaringan ikat silang yang banyak sehingga dapat menghambat laju difusi air ke mikrokapsul dan menghambat peregangan jaringan polimer sehingga penyerapannya rendah. Sebaliknya, konsentrasi larutan kitosan yang rendah membuat sedikitnya jaringan taut silang yang terbentuk sehingga memudahkan air untuk diserap. Sama halnya dengan perubahan konsentrasi larutan glutaraldehida, semakin tinggi konsentrasi glutaraldehida daya serap mikrokapsul pupuk NPK terhadap air semakin kecil.

Daya serap air tertinggi diperoleh dari mikrokapsul pupuk NPK yang dibuat dari konsentrasi larutan kitosan $1 \%(\mathrm{~b} / \mathrm{v})$ sebesar $80 \%$, sebaliknya daya serap air terendah dari mikrokapsul pupuk NPK dari konsentrasi larutan kitosan 4\% (b/v) yaitu sebesar 30,5\%. Hasil yang sama dilaporkan oleh Guo et al. (2006) peningkatan jumlah glutaraldehida dapat menurunkan daya serap air karena densitas ikat silang yang tinggi dan juga meningkatkan ikat silang jaringan polimer yang dapat menghambat peregangan rantai 
polimer. Penelitian yang telah dilaporkan oleh Pramono et al. (2014) yang menyatakan bahwa peningkatan konsentrasi polimer dapat meningkatkan gugus hidrofilik sehingga meningkatkan daya serap air, tetapi dengan menambahkan polimer dengan gugus hidrofobik dapat menurunkan daya serap air. Adapun pada penelitian ini peningkatan konsentrasi larutan kitosan menurunkan daya serap air karena larutan di taut silang dengan glutaraldehida. Peningkatan konsentrasi larutan kitosan juga meningkatkan interaksi reaksi taut silang antara gugus amina dan aldehida sehingga mikrokapsul menjadi lebih padat dan menyebabkan menurunnya daya serap air.

Peningkatan agen crosslink juga dapat meningkatkan struktur jaringan sehingga mengurangi ruang untuk menampung air (Liang and Liu, 2006). Hal inilah yang menyebabkan peningkatan konsentrasi glutaraldehida menurunkan daya serap air.

\section{Karakterisasi mikrokapsul pupuk NPK}

\section{Scanning Electron Microscope (SEM)}

Analisis morfologi mikrokapsul pupuk NPK bertujuan untuk menunjukkan bentuk mikrokapsul yang dihasilkan dari reaksi silang antara larutan kitosan dengan larutan glutaraldehida. Bentuk mikrokapsul pupuk NPK yang terbentuk dapat ditunjukkan pada Gambar 3.

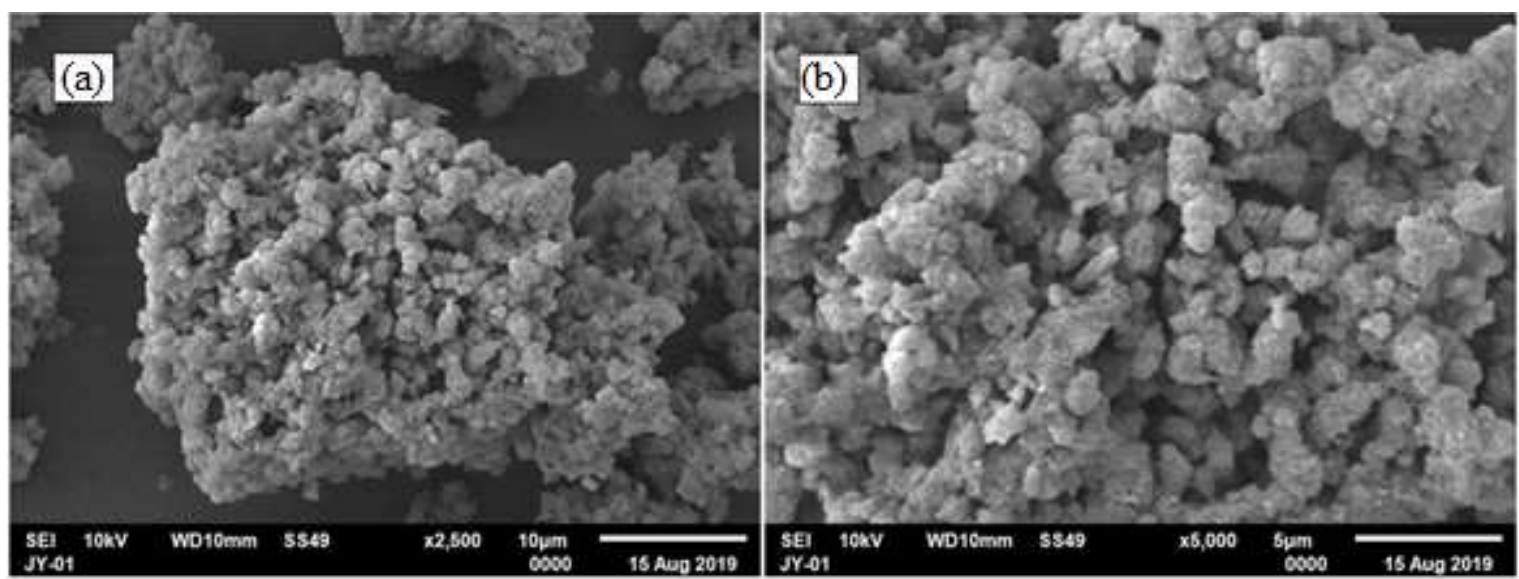

Gambar 3. Karakterisasi morofologi mikrokapsul pupuk NPK yang dibuat dari konsentrasi larutan kitosan dan glutaraldehida sebesar 2\% (w/v) dan 5\% (v/v) untuk (a) mikrokapsul pupuk NPK yang diperbesar sampai 2500 dan (b) diperbesar sampai 5000x

Gambar 3 menunjukkan bahwa bentuk mikrokapsul pupuk NPK sudah menunjukkan hanya terdapat beberapa berbentuk bulat dan masih banyak yang bentuknya tidak beratura dan dengan permukaan mikrokapsul pupuk NPK yang tidak halus. Bentuk yang tidak bulat sempurna ini kemungkinan disebabkan oleh pembuatan mikrokapsul yang 
tidak diawali dengan pembuatan emulsi. Penelitian ini membuat mikrokapsul pupuk NPK dengan meneteskan campuaran larutan kitosan dan pupuk NPK cair sedikit demi sedikit pada larutan agen crosslink sambil dilakukan pengadukan. Akan tetapi secara keseluruhan dapat disimpulkan bahwa mikrokapsul telah terbentuk dengan baik walaupun tidak mempunyai bentuk geometri bulat sempurna.

\section{Fourier-Transform Infrared Spectroscopy (FTIR)}

Analisis interaksi antara gugus amina dari kitosan dengan gugus aldehida dari glutaraldehida dapat dilihat pada Gambar 4.

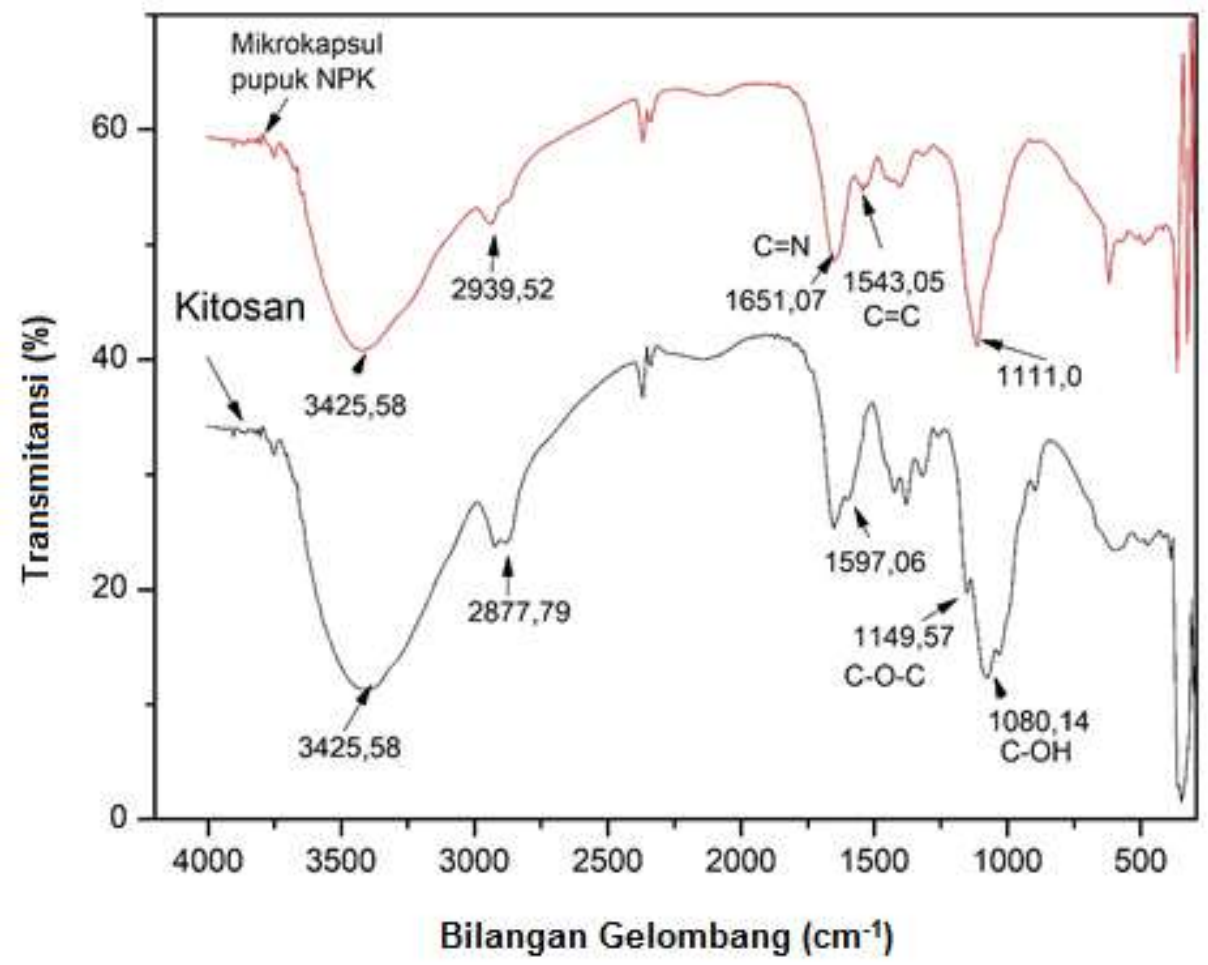

Gambar 4. Analisis FTIR untuk kitosan dan mikrokapsul pupuk NPK yang dibuat dari konsentrasi larutan kitosan 2\% (w/v) dan glutaraldehida 5\% (v/v).

Gambar 4. menunjukkan bahwa munculnya peak baru pada mikrokapsul pupuk NPK yang terjadi pada peak $1651,07 \mathrm{~cm}^{-1}$ dikaitkan dengan ikatan imine $(\mathrm{C}=\mathrm{N})$ yang terbentuk dari ikatan gugus fungsi aldehida dari glutaraldehida dan gugus amina dari kitosan dan peak 1543,05 $\mathrm{cm}^{-1}$ yang menunjukkan ikatan etilenat $(\mathrm{C}=\mathrm{C})$. Ikatan ini terbentuk karena resonansi terbentuknya ikatan imina dari gugus aldehida (glutaraldehida) dan amina (kitosan). Pada peak-peak yang lain menunjukkan bahwa mikrokapsul pupuk NPK hampir sama dengan kitosan. Peak utama dari Gambar 4 adalah sebagai berikut: $3425,58 \mathrm{~cm}^{-1}$ untuk N-H stretching dan O-H vibration; $2939,52 \mathrm{~cm}^{-1}$ berkaitan dengan peregangan simetris $\mathrm{CH}_{3}$, getaran lentur $\mathrm{C}-\mathrm{O}-\mathrm{C}$ pada $1149,57 \mathrm{~cm}^{-1}$; dan getaran peregangan $\mathrm{C}-\mathrm{OH}$ pada $1080,14 \mathrm{~cm}^{-1}$. Penentuan jenis ikatan berdasarkan bilangan 
gelombang yang dihasilkan dari analisis FTIR untuk kitosan dan mikrokapsul pupuk NPK mengacu pada penelitian yang telah dilaporkan oleh Li et al. (2013).

Gambar 4 menunjukkan bahwa muncul peak baru yang berkaitan dengan terjadi reaksi taut silang antara gugus amina dari kitosan dengan gugus aldehida dari glutaraldehida. Gugus aldehida membentuk ikatan kovalen imina dengan gugus amina dari kitosan karena resonansi yang terbentuk dengan etilenat ganda yang berdekatan melalui reaksi Schiff (Gonçalves et al., 2005).

\section{Uji release pupuk NPK}

Penentuan jumlah pupuk NPK yang lepas dari mikrokapsul dapat dilakukan uji release. Uji release ini digunakan untuk menentukan kemampuan dari kitosan dari ditaut silang dengan glutaraldehida untuk mengontrol pupuk NPK yang release dari mikrokapsul secara perlahan dalam waktu yang lama. Pada penelitian ini waktu release yang digunakan sampai dengan 30 hari (720 jam). Pada penelitian ini dilakukan uji release dalam medium air seperti yang ditunjukkan pada Gambar 5 dan 6 .

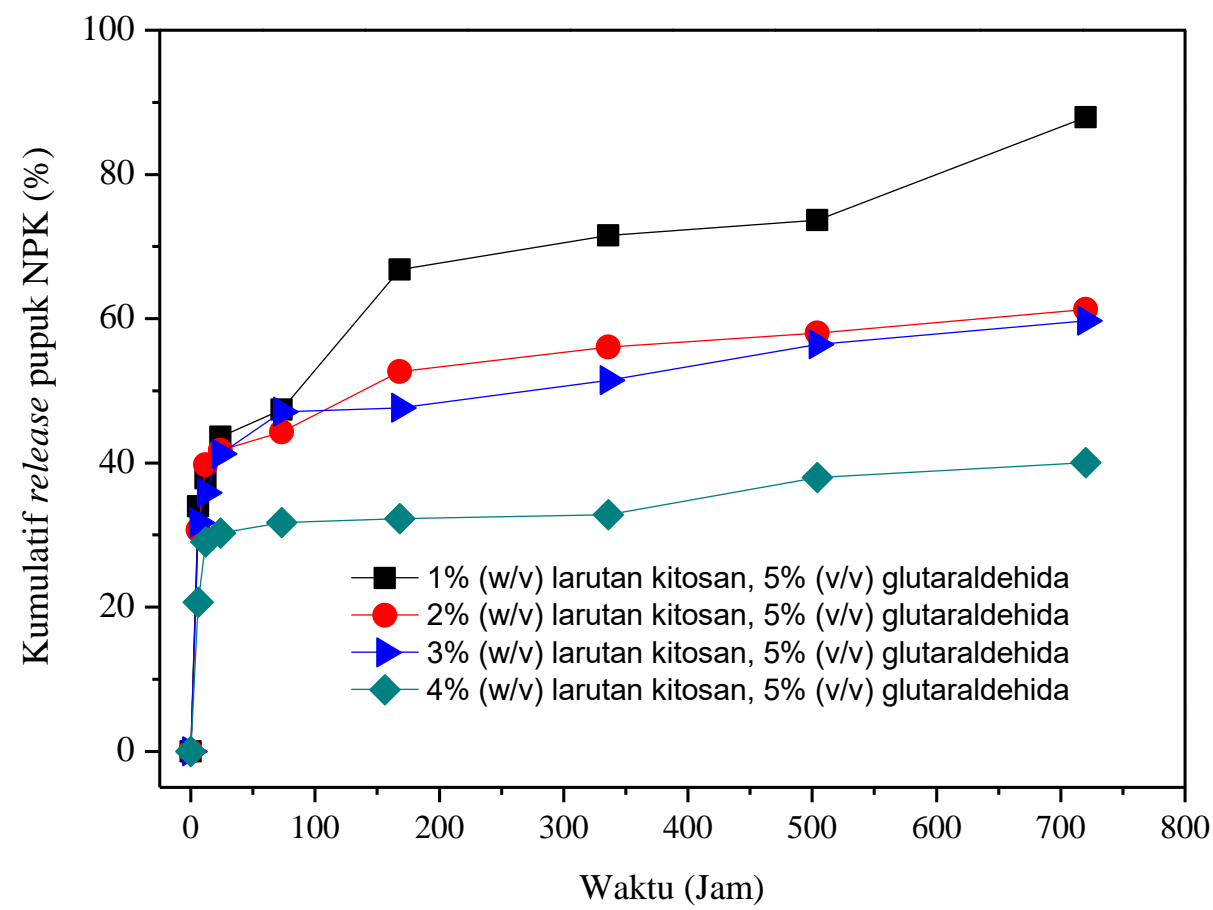

Gambar 5. Jumlah pupuk NPK yang release dari mikrokapsul karena pengaruh perubahan konsentrasi larutan kitosan. Mikrokapsul pupuk NPK yang dibuat dari reaksi taut silang antara larutan kitosan dengan 5\% (v/v) konsentrasi larutan glutaraldehida

Gambar 5 menunjukkan bahwa perubahan konsentrasi larutan kitosan sebagai penyalut mikrokapsul pupuk NPK berpengaruh pada jumlah pupuk NPK yang release. Gambar 5 memperlihatkan bahwa semakin tinggi konsentrasi larutan kitosan menghasilkan 
pupuk NPK yang release semakin kecil. Perbedaan yang signifikan ditunjukkan pada konsentrasi larutan kitosan sebesar 4\% (b/v) menghasilkan kumulatif release sekitar $40 \%$ dan nilai tersebut hampir setengahnya dari kumulatif release pupuk NPK yang menggunakan konsentrasi kitosan $1 \%(\mathrm{~b} / \mathrm{v})$. Adapun perbedaan yang tidak signifikan dari kumulatif release dari mikrokapsul pupuk NPK yang dibuat dari larutan kitosan dengan 2 dan $3 \%(\mathrm{~b} / \mathrm{v})$ yaitu 61,29 dan $59,71 \%$. Perbedaan yang signifikan ini disebabkan oleh perubahan konsentrasi larutan kitosan yang tidak jauh berbeda. Kepadatan dinding mikrokapsul yang hampir sama dari konsentrasi larutan kitosan 2 dan 3\% (b/v). Peningkatan konsentrasi larutan kitosan membuat viskositasnya semakin meningkat dan membuat dinding mikrokapsul menjadi lebih padat yang memungkinkan pupuk NPK yang release menjadi lebih rendah (Jayanudin, 2019a; Dini et al., 2003).

Peningkatan kosentrasi larutan menyebabkan jaringan ikat silang antara gugus amina dan aldehida menjadi semakin banyak dan menjadi lebih rapat. Hal inilah yang kemungkinan pupuk NPK yang release menjadi lebih rendah. Pada konsentrasi larutan kitosan $1 \%(\mathrm{~b} / \mathrm{v})$, menghasilkan pupuk NPK yang release paling tinggi yaitu sebesar 87,93\% dibandingkan dengan konsentrasi 2, 3, dan 4\% (b/v). Rendahnya konsentrasi larutan kitosan membuat struktur jaringan ikat silang masih sedikit yang menyebabkan mudahnya terjadi rileksasi jaringan polimer yang membuat pupuk NPK menjadi lebih mudah untuk release. Hasil yang sama juga telah dilaporkan oleh Hussain et al. (2012) yang menyatakan bahwa peningkatan konsentrasi menyebabkan pupuk urea yang release dari kitosan yang ditautsilang dengan genipin menjadi lebih rendah karena disebabkan oleh peningkatan ketebalan dinding mikrokapsul.

Perubahan konsentrasi larutan glutaraldehida juga berpengaruh pada nilai pupuk NPK yang release dari mikrokapsul. Gambar 6 menunjukkan bahwa semkin tinggi konsentrasi larutan glutaraldehida, kumulatif release pupuk NPK menjadi lebih rendah. Kumulatif release pupuk NPK yang terrendah diperoleh dari $10 \%$ (v/v) konsentrasi larutan glutaraldehida sebesar 39,51\% sedangkan kumulatif release tertinggi sebesar 69,96\% dari konsentrasi larutan glutaraldehida sebesar 3\% (v/v).

Glutaraldehida sebagai agen crosslink berfungsi pengikat gugus amina dari kitosan. Adanya ikatan tersebut menyebabkan viskositas menjadi meningkat dan menyebabkan sifat hidrofobik matrik kitosan menjadi meningkat, serta menyebabkan penurunan mobilitas rantai makromolekul (Patel and Patel, 2014; Dinarvand et al., 2005; Jayanudin et al., 2019b). Meningkatnya konsentrasi kitosan mampu meningkatkan interaksi ikatan 
silang antara glutaraldehida dengan kitosan sehingga dapat meningkatkan pembentukan ikatan silang baru dan membuat dinding mikrokapsul lebih kuat (Jayanudin et al., 2019b).

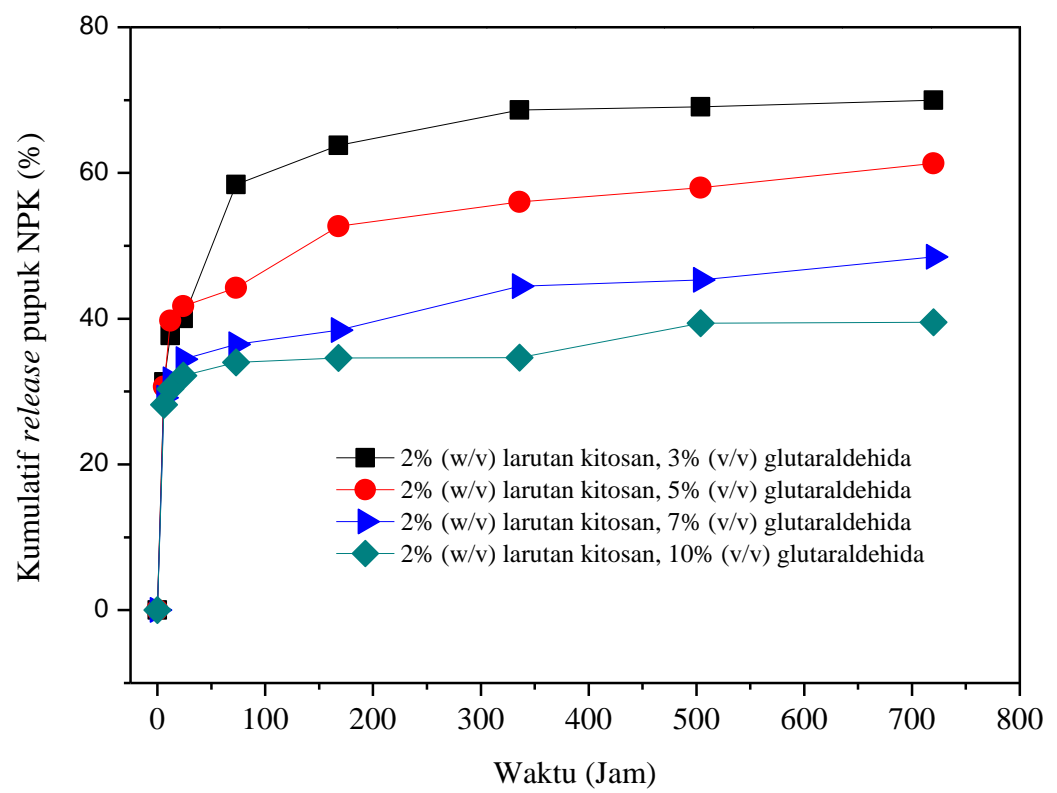

Gambar 6. Pengaruh konsentrasi larutan glutaraldehida terhadap kumulatif release pupuk NPK dari mikrokapsul yang dibuat dari larutan kitosan dengan kosentrasi $2 \%(\mathrm{w} / \mathrm{v})$

\section{Kinetika release pupuk NPK dari mikrokapsul}

Kinetika release dihitung menggunakan persamaan 3-7, kinetika release ini digunakan untuk memodelkan proses release sebelum diaplikasikan (Dash et al., 2010). Penentuan konstanta kinetika release dihitung menggunakan metode analisis regresi nonlinier. Model yang sesuai ditentukan dengan nilai koefisien korelasi tertinggi $\left(\mathrm{R}^{2}\right)$. Nilai konstanta kinetika release dari model-model pada persamaan 3-7 seperti $\mathrm{k}_{0}, \mathrm{k}_{1}, \mathrm{k}_{\mathrm{H}}, \mathrm{k}_{\mathrm{K}-\mathrm{P}}$, dan $\mathrm{k}_{\mathrm{H}-\mathrm{C}}$ dapat dilihat pada Tabel 1.

Tabel 1. menunjukkan bahwa nilai $\mathrm{R}^{2}$ tertinggi diperoleh dari model order 1 dengan nilai $\mathrm{R}^{2}$ sebesar 0,89 yaitu pada mikrokapsul NPK yang dibuat dari larutan kitosan dengan konsentrasi $1 \%(\mathrm{~b} / \mathrm{v})$ dan larutan glutaraldehida pada konsentrasi 5\% (v/v). Adapun perngaruh konsentrasi larutan kitosan dan glutaraldehida pada order satu mempunyai nilai $\mathrm{R}^{2}$ yang rendah mulai dari $0,36-0,63$. Model kinetika release order satu menggambarkan penyerapan dan/atau eliminasi beberapa inti mikrokapsul dan aplikasi model ini untuk sediaan inti mikrokapsul yang larut dalam air dalam matrik berpori (Dash et al., 2010). Berdasarkan keterangan ini menunjukkan bahwa mikrokapsul dari konsentrasi larutan kitosan $1 \%(\mathrm{w} / \mathrm{v})$ dan konsentrasi larutan glutaraldehida 5\% mempunyai penyerapan yang tinggi karena matrik yang berpori. Model kinetika release yang mempunyai nilai $\mathrm{R}^{2}$ yang 
mengalami perubahan yang tidak signifikan adalah model Higuchi. Model ini menggambarkan release inti mikrokapsul secara difusi, dimana mikrokapsul tidak mengalami proses pembengkakan (swelling). Nilai $\mathrm{R}^{2}$ yang dihasilkan mulai dari $0,46-$ 0,85 .

Tabel 1. Konstanta kinetika release pupuk NPK dari mikrokapsul pada berbagai konsentrasi larutan kitosan dan larutan glutaraldehida

\begin{tabular}{|c|c|c|c|c|c|c|c|c|c|c|c|}
\hline \multirow[t]{2}{*}{ Variabel } & \multicolumn{2}{|c|}{ Order nol } & \multicolumn{2}{|c|}{ Order satu } & \multicolumn{2}{|c|}{ Higuchi } & \multicolumn{2}{|c|}{$\begin{array}{l}\text { Hixon- } \\
\text { Crowell }\end{array}$} & \multicolumn{3}{|c|}{ Korsmeyer-Peppas } \\
\hline & $\mathrm{K}_{0}$ & $\mathrm{R}^{2}$ & $\mathrm{~K}_{1}$ & $\mathrm{R}^{2}$ & $\mathrm{~K}_{\mathrm{H}}$ & $\mathrm{R}^{2}$ & $\mathrm{~K}_{\mathrm{H}-\mathrm{C}}$ & $\mathrm{R}^{2}$ & $\mathrm{~K}_{\mathrm{K}-\mathrm{P}}$ & $\mathrm{n}$ & $\mathrm{R}^{2}$ \\
\hline $\begin{array}{l}1 \%(\mathrm{~b} / \mathrm{v}) \\
\text { larutan } \\
\text { kitosan, } \\
5 \%(\mathrm{v} / \mathrm{v}) \\
\text { glutaraldehida }\end{array}$ & 0,0009 & 0,69 & 0,0023 & 0,89 & 2,57 & 0,85 & 0,0025 & 0,84 & 4,898 & 0,50 & 0,67 \\
\hline $\begin{array}{l}2 \%(\mathrm{~b} / \mathrm{v}) \\
\text { larutan } \\
\text { kitosan, } \\
5 \%(\mathrm{v} / \mathrm{v}) \\
\text { glutaraldehida }\end{array}$ & 0,0005 & 0,48 & 0,0009 & 0,62 & 1,61 & 0,67 & 0,011 & 0,57 & 5,129 & 0,45 & 0,60 \\
\hline $\begin{array}{l}3 \%(\mathrm{~b} / \mathrm{v}) \\
\text { larutan } \\
\text { kitosan, } \\
5 \%(\mathrm{v} / \mathrm{v}) \\
\text { glutaraldehida }\end{array}$ & 0,0005 & 0,62 & 0,0009 & 0,62 & 1,52 & 0,66 & 0,0005 & 0,57 & 5,129 & 0,44 & 0,59 \\
\hline $\begin{array}{l}4 \%(\mathrm{~b} / \mathrm{v}) \\
\text { larutan } \\
\text { kitosan, } \\
5 \%(\mathrm{v} / \mathrm{v}) \\
\text { glutaraldehida }\end{array}$ & 0,0003 & 0,39 & 0,0005 & 0,47 & 0,94 & 0,56 & 0,0006 & 0,45 & 4,467 & 0,39 & 0,57 \\
\hline $\begin{array}{l}2 \%(\mathrm{~b} / \mathrm{v}) \\
\text { larutan } \\
\text { kitosan, } \\
3 \%(\mathrm{v} / \mathrm{v}) \\
\text { glutaraldehida }\end{array}$ & 0,0006 & 0,51 & 0,0014 & 0,63 & 2,102 & 0,73 & 0,0016 & 0,59 & 4,898 & 0,49 & 0,65 \\
\hline $\begin{array}{l}2 \%(\mathrm{~b} / \mathrm{v}) \\
\text { larutan } \\
\text { kitosan, } \\
7 \%(\mathrm{v} / \mathrm{v}) \\
\text { glutaraldehida }\end{array}$ & 0,0005 & 0,45 & 0,0005 & 0,55 & 1,18 & 0,62 & 0,0008 & 0,52 & 4,898 & 0,41 & 0,57 \\
\hline $\begin{array}{l}2 \%(\mathrm{~b} / \mathrm{v}) \\
\text { larutan } \\
\text { kitosan, } \\
10 \%(\mathrm{v} / \mathrm{v}) \\
\text { glutaraldehida }\end{array}$ & 0,0003 & 0,3 & 0,0005 & 0,36 & 0,85 & 0,46 & 0,0005 & 0,34 & 5,082 & 0,38 & 0,52 \\
\hline
\end{tabular}




\section{KESIMPULAN}

Mikrokapsul pupuk NPK yang dibuat dari larutan kitosan dan ditaut silang dengan larutan glutaraldehida telah berhasil dilakukan. Peningkatan konsentrasi larutan kitosan dan larutan glutaraldehida dapat meningkatkan yield dan menurunkan daya serap air dari mikrokapsul pupuk NPK sehingga pupuk NPK yang release juga menjadi menurun. Peningkatan kumualtif release secara teratur menunjukkan keberhasilan mikrokapsul pupuk NPK ini untuk mengontrol release dari pupuk NPK. Walaupun dalam analisis karakterisasi morfologi, mikrokapsul pupuk NPK belum memiliki bentuk geometri bulat sempurna. Perhitungan kinetika release menunjukkan bahwa model yang sesuai untuk release pupuk NPK berdasarkan nilai $\mathrm{R}^{2}$ tertinggi adalah untuk model order satu dan model Higuchi dari mikrokapsul yang dipreparasi dari konsentrasi larutan kitosan sebesar 1( (b/v) dan 5\% (v/v) dari konsentrasi larutan glutaraldehida.

\section{UCAPAN TERIMAKASIH}

Kami mengucapkan terima kasih karena penelitian ini didanai dari Penelitian Dasar Unggulan IPTEK (PDUI) melalui pendanaan Research Grant 4 in 1 IsDB Project, Universitas Sultan Ageng Tirtayasa dengan No. Kontrak: B/60/UN43.9/PT.01.03/2019.

\section{DAFTAR PUSTAKA}

Chen, M., Li, Z., Huang, P., Li, X., Qu, J., Yuan, W., and Zhang, Q., 2018. Mechanochemical Transformation of Apatite to Phosphoric Slow-Release Fertilizer and Soluble Phosphate. Process Safety and Environmental Protection 144, 91-96. doi: 10.1016/j.psep.2017.12.008.

Danarto, Y.C., Nugrahey, A., and Noviani, S.M., 2017. Kinetika Slow Release Pupuk Urea Berlapis Chitosan Termodifikasi. Equilibrium 1(2), 1-5.

Dash, S, Murthy, P.N., Nath, L., and Chowdhury, P., 2010, Kinetic Modeling on Drug Release from Controlled Drug Delivery Systems, Acta Poloniae Pharmaceutica 67(3), 217-23.

Dinarvand, R., Mahmoodi, S., Farboud, E., Salehi, M., and Atyabi, F., 2005. Preparation of Gelatin Microspheres Containing Lactic Acid-Effect of Cross-Linking on Drug Release, Acta Pharmaceutica (Zagreb, Croatia) 55 (1), 57-67.

Dini, E., Alexandridou, S., and Kiparissides, C., 2003. Synthesis and Characterization of Cross-Linked Chitosan Microspheres for Drug Delivery Applications. Journal of Microencapsulation 20, 375-385. doi: 10.3109/02652040309178076.

Dozie-Nwachukwu, S.O., Danyuo, Y., Obayemi, J.D., Odusanya, O.S., Malatesta, K., and Soboyejo, W.O., 2017. Extraction and Encapsulation of Prodigiosin in Chitosan Microspheres for Targeted Drug Delivery. Materials Science and Engineering C 71, 268-278. doi: 10.1016/j.msec.2016.09.078. 
El-Nashar, D.E., Rozik, N.N., Soliman, A.M., and Helaly, F., 2016. Study The Release Kinetics of Curcumin Released from PVA/Curcumin Composites and Its Evaluation Towards Hepatocarcinoma. Journal of Applied Pharmaceutical Science 6(7), 67-72. doi: 10.7324/JAPS.2016.60710.

Gonçalves, V.L., Laranjeira, M.C.M., and Fávere, V.T., 2005, Effect of Crosslinking Agents on Chitosan Microspheres in Controlled Release of Diclofenac Sodium, Polímeros: Ciência e Tecnologia 15(1), 6-12. doi: 10.1590/S010414282005000100005 .

Guo, H., White, J.C., Wang, Z., and Xing, B., 2018. Nano-Enabled Fertilizers to Control The Release and Use Efficiency of Nutrients. Current Opinion in Environmental Science \& Health 6, 77-83. doi: 10.1016/j.coesh.2018.07.009.

Guo, M., Liu, M., Liang, R., and Niu, A., 2006. Granular Urea-Formaldehyde SlowRelease Fertilizer with Superabsorbent and Moisture Preservation. Journal of Applied Polymer Science 99(6), 3230-3235. doi: 10.1002/app.22892.

Himmah, N.I.F,, Djajakirana, G., and Darmawan, D. 2018. Nutrient Release Performance of Starch Coated NPK Fertilizers and Their Effects on Corn Growth. SAINS TANAH - Journal of Soil Science and Agroclimatology 15(2), 104-114. doi: 10.15608/stjssa.v15i2.19694.

Hussain, M.R., Devi, R.R., and Maji, T.K., 2012. Controlled Release of Urea from Chitosan Microspheres Prepared by Emulsification and Cross-Linking Method. Iranian Polymer Journal (English Edition) 21(8), 473-479. doi: 10.1007/s13726012-0051-0.

Jing, W., Song, L., Yukun, Q., Xiaolin, C., Rong'e, X., Huahua, Y., Kecheng, L., and Pengcheng, L., 2017. Preparation and Characterization of Controlled-Release Fertilizers Coated with Marine Polysaccharide Derivatives. Chinese Journal of Oceanology and Limnology 35, 1086. doi: 10.1007/s00343-017-6074-9.

Jayanudin., Fahrurrozi, M., Wirawan, S.K., and Rochmadi. 2018. Controlled Release Evaluation of Red Ginger Oleoresin Encapsulation Using Simulated Gastric Fluid (SGF). Research Journal of Pharmacy and Technology 11(8), 3431-3436. doi: 10.5958/0974-360X.2018.00633.9.

Jayanudin., Fahrurrozi, M., Wirawan, S.K., and Rochmadi. 2019a. Antioxidant Activity and Controlled Release Analysis of Red Ginger Oleoresin (Zingiber officinale var rubrum) Encapsulated in Chitosan Cross-Linked by Glutaraldehyde Saturated Toluene. Sustainable Chemistry and Pharmacy 12, 100132. doi: 10.1016/j.scp.2019.100132.

Jayanudin., Fahrurrozi, M., Wirawan, S.K., and Rochmadi. 2019b. Mathematical Modeling of The Red Ginger Oleoresin Release from Chitosan-Based Microcapsules Using Emulsion Crosslinking Method. Engineering Science and Technology, an International Journal 22(2) 458-467. doi: 10.1016/j.scp.2019.100132.

Li, B., Shan, C.L., Zhou, Q., Fang, Y., Wang, T.L., Xu, F., Han, L.R., Ibrahim, M., Guo, L.B., Xie, G.L., and Sun, G.C., 2013. Synthesis, Characterization, and Antibacterial Activity of Cross-Linked Chitosan-Glutaraldehyde. Marine Drugs 11, 1534-1552. doi: $10.3390 / \mathrm{md} 11051534$. 
Liang, R and Liu, M. 2006. Preparation and Properties of Coated Nitrogen Fertilizer with Slow Release and Water Retention. Industrial \& Engineering Chemistry Research 45(25), 8610-8616. doi: 10.1021/ie060705v.

Olad, A., Zebhi, H., Salari, D., Mirmohseni, A., and Reyhani Tabar, A., 2018. SlowRelease NPK Fertilizer Encapsulated by Carboxymethyl Cellulose-Based Nanocomposite with The Function of Water Retention in Soil. Materials Science \& Engineering C 90, 333-340. doi: 10.1016/j.msec.2018.04.083.

Patel, K.S..and Patel, M.B., 2014. Preparation and Evaluation of Chitosan Microspheres Containing Nicorandil, International Journal of Pharmaceutical Investigation 4(1), 32-37. doi: 10.4103/2230-973X.127738.

Perez, J.J, and Francois, N.J., 2016. Chitosan-Starch Beads Prepared by Ionotropic Gelation as Potential Matrices for Controlled Release of Fertilizers. Carbohydrate Polymers 148, 134-142. doi: 10.1016/j.carbpol.2016.04.054.

Pramono, E., Purnawan, C., Hidayat, Y., Wulansari, J., and Wahyuningsih, S., 2014. Composite of Chitosan Vanilin/Sulfonated Polystyrene as Polymer Electrolyte Membranes: Cationic Exchange Capacity, Swelling Degree and Thermal Properties. ALCHEMY Jurnal Penelitian Kimia 10(2), 116-129. doi: 10.20961/alchemy.10.2.55.116-129.

Savana, R.T and Maharani, D.K., 2018. Analisis Komposisi Unsur Pupuk Lepas Lambat Kitosan-Silika- Glutaraldehid. Unesa Journal of Chemistry 7(1), 21-24.

Sempeho, S.I., Kim, H.T., Mubofu, E., and Hilonga, A., 2014. Meticulous Overview on the Controlled Release Fertilizers. Advances in Chemistry 2014, 1-16. doi: $10.1155 / 2014 / 363071$.

Wu, L., and Liu, M., 2008. Preparation and Properties of Chitosan-Coated NPK Compound Fertilizer with Controlled release and Water-Retention. Carbohydrate Polymers 72(2), 240-247. doi: 10.1016/j.carbpol.2007.08.020. 